\title{
Pain situations among working adults and the educational needs identified: an exploratory survey via WeChat
}

\author{
Yajie Li and Mimi M. Y. Tse
}

\begin{abstract}
Objectives: The aim of this study is to 1) investigate the pain situation among working adults in China; 2) explore the self-initiate pain reliving strategies applied by working adults; and 3) collect people's interests and suggestions to the topics of the online pain education program.

Methods: This is an exploratory survey through WeChat. The study was conducted from May 2018 to December 2018. Participants were recruited following the snowball sampling. In total of 664 people were recruited and 502 satisfied the criteria. SPSS was used for data analysis. Descriptive statistical analysis were used to present the utilization of pain treatments and suggested topics. Chi-square test, independent multiple logistic regression and Spearman's correlation were used to analysis the data.
\end{abstract}

Results: The overall incidence of pain among the participants is $45 \%$ and higher among female (63\%) than male (37\%). Neck $(68.72 \%, 4.10 \pm 2.31)$, shoulder $(62.56 \%, 3.78 \pm 2.41)$ and head $(49.34 \%, 4.23 \pm 2.52)$ are reported as the most common and severe pain sites. Working is affected by pain and the results show that there is a negative correlation between pain intensity and work ( $r s=-0.194$ ) among the working population. Non-pharmacological treatments $(55.77 \%)$ were chosen more by pain suffers. Totally $63.39 \%$ of participants show interests in the online pain education program and physical and psychological impact of pain is the most suggested topic (22.51\%).

Conclusion: The pain prevalence is high among working adults in China. Impact of pain on work is a significant problem for the working adults. It is important to identify people at risk and deliver timely intervention to reduce pain. People showed their willingness in joining the online program. Therefore, future online pain education program can be developed.

Keywords: Educational need, Pain, Working adults, WeChat

\section{Introduction}

Pain is a common and major public health problem and is negatively impact individual's quality of life from different aspects including physical, psychological and social [1-4]. It was demonstrated that pain can restrict daily activities, decrease appetite, impair sleep and lead to depression, anxiety. Relationship strain, family burden, social isolation and even financial difficulties can be result of pain. The estimation of pain prevalence was ranging from 2 to $45 \%$ among the general population [5]. In Asia, pain among adults was reported ranging from 7.1 to $61 \%$ [6]. Study reported the pain prevalence

\footnotetext{
* Correspondence: mimi.tse@polyu.edu.hk

School of Nursing, The Hong Kong Polytechnic University, Kowloon, Hong Kong, China
}

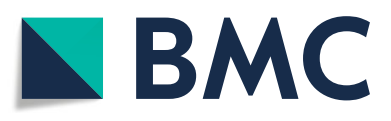

(c) The Author(s). 2019 Open Access This article is distributed under the terms of the Creative Commons Attribution 4.0 International License (http://creativecommons.org/licenses/by/4.0/), which permits unrestricted use, distribution, and reproduction in any medium, provided you give appropriate credit to the original author(s) and the source, provide a link to the Creative Commons license, and indicate if changes were made. The Creative Commons Public Domain Dedication waiver (http://creativecommons.org/publicdomain/zero/1.0/) applies to the data made available in this article, unless otherwise stated. accessible in China show that the data was scarce [8].

Pain management programs had been conducted to control pain and its potential negative impact on quality of living and quality of life and effectiveness have been proved [1, 2, 9-13]. Nicholes et al. [14] used a face-toface pain self-management program named "Manage your pain" among elderly in Australia. A copy of selfmanagement text was provided to the participants and they were encouraged to perform the exercise and skills during the treatment session. Pain intensity, depression, pain-related disability and self-efficacy were found significantly improved.

Internet, as an innovative approach, can meet a large patient's population with no region restriction. Educational 
and therapeutic programs delivered through internet is becoming increasingly popular [15]. Internet-delivered programs using the same principles, provide same evidence-based treatments and teach same skills as the face-to-face programs $[1,9,16]$ but can overcome the barriers of face-to-face approach such as long distance, long waiting time, direct and indirect cost and insufficient of trained health professionals [1, 9, 17]. Dear et al. [9] evaluate the efficacy and acceptability of a validated internet-delivered chronic pain management program "The Pain Course". The program provide therapeutic information and teaches self-management skills through internet. Results show that both physical and psychological outcomes were significantly improved with high acceptability. However, only one online pain management program is available in China which is for female teenagers to selfmanage dysmenorrhea [18] even if China has more than 829 million internet users [19].

To access the internet, WeChat is a popular, free and secure mobile application which has attracted more than 900 million active users in China [20, 21]. The application includes mobile text and voice messaging communication service. Besides, it is also a platform to access internet. Spreading information and providing service can be easily achieved using WeChat.

The present study was carried out to 1 ) investigate the pain situation among working adults in China; 2) explore the self-initiate pain relieving strategies applied by working adults; and 3) explore people's interests and potential topics for the future online pain management program.

\section{Methods}

\section{Study design}

It is a survey using self-administered questionnaire delivered through internet. Data was collected in China from May 2018 to December 2018.

\section{Sample and procedure}

To represent the 7.8 billion working population in China with 95\% confidence level and 5\% margin of error, the sample size estimation of this exploratory survey was 385 .

People satisfy the following criteria were regarded as eligible: 1) aged between 16 and 60;2) have a full-time job; 3) resident of China and can understand Chinese; 4) own a smartphone which can assess the internet. Patients in hospital, experiencing a drug addiction problem or having mental illness were excluded. Participants were recruited mainly from three cities: Guangzhou, Xi'an and Xining using snowball sampling.

After the ethical approval was obtained from The Hong Kong Polytechnic University, the questionnaire attached with the information sheet was first sent to a group of friends and relatives with full-time job through WeChat, and then they were asked to forward the questionnaire into different WeChat groups to recruit participants. People who completed the questionnaire were also encouraged to forward to others. All participants' consent was collected online. After reading the information sheet, people who agree to join in were required to click "Agree" button to start the survey, otherwise they would be regarded as do not agree to participate and the online survey would be unavailable. Besides, several questions in the questionnaire were set with condition mainly in the pain situation and demographic data part, the questionnaire would be automatically and directly submitted once participants chose the choices indicate the ineligibility and this means people who are not eligible cannot finish the complete survey. The questionnaire was required to be completed online and the data was recorded at the backstage of WeChat which is accessible for the researchers which is secure. The data file can be directly downloaded into SPSS format from WeChat and the accuracy is guaranteed. Participation was voluntary as there was no remuneration for the participants. Study flow shows in Fig. 1.

\section{Questionnaire}

The questionnaire was adopted from a previous pain management study [22] which including 5 parts:1) pain situation, 2) pain treatment, 3) public pain service and education, 4) internet accessibility and 5) demographic data. Five experts including one registered nurse, two physiotherapists, one occupational therapist and an expert of traditional Chinese medicine were invited to assess the validity using Content Validity Index for Items in which higher score indicate higher relevant. The overall Validity Index for Items was reported 0.8-1.0. Lawshe [23] suggests an index of .99 (at least), when the number of experts is 7 or less. Test-retest reliability was assessed by 5 pain suffers with two-week interval. The Intra-class Correlation Coefficient ranged from 0.802 to 0.971 .

In part 1, pain was assessed by modifying and using part of Brief Pain Inventory-Short Form, a brief, selfadministered questionnaire developed to assess the pain intensity, prevalence and impact [24-26] Pharmacological and non-pharmacological treatments that participants used in relieving pain in the previous period was asked in the pain treatment part. In part 2, participants were asked to score the self-perceived effectiveness of the different methods, with 0 indicating the lowest self-perceived effectiveness and 5 indicating the highest. In part 3, assessment of how participants think about the public service and education existing now was included. The source to get public service was assessed by using a multiple-choice question "where can you get the information about pain management and education?" the answers including website, leaflet, medical workers, poster, magazine and friends. The quantitative of existing public pain service and education was asked using single-choice questions: "Do you 


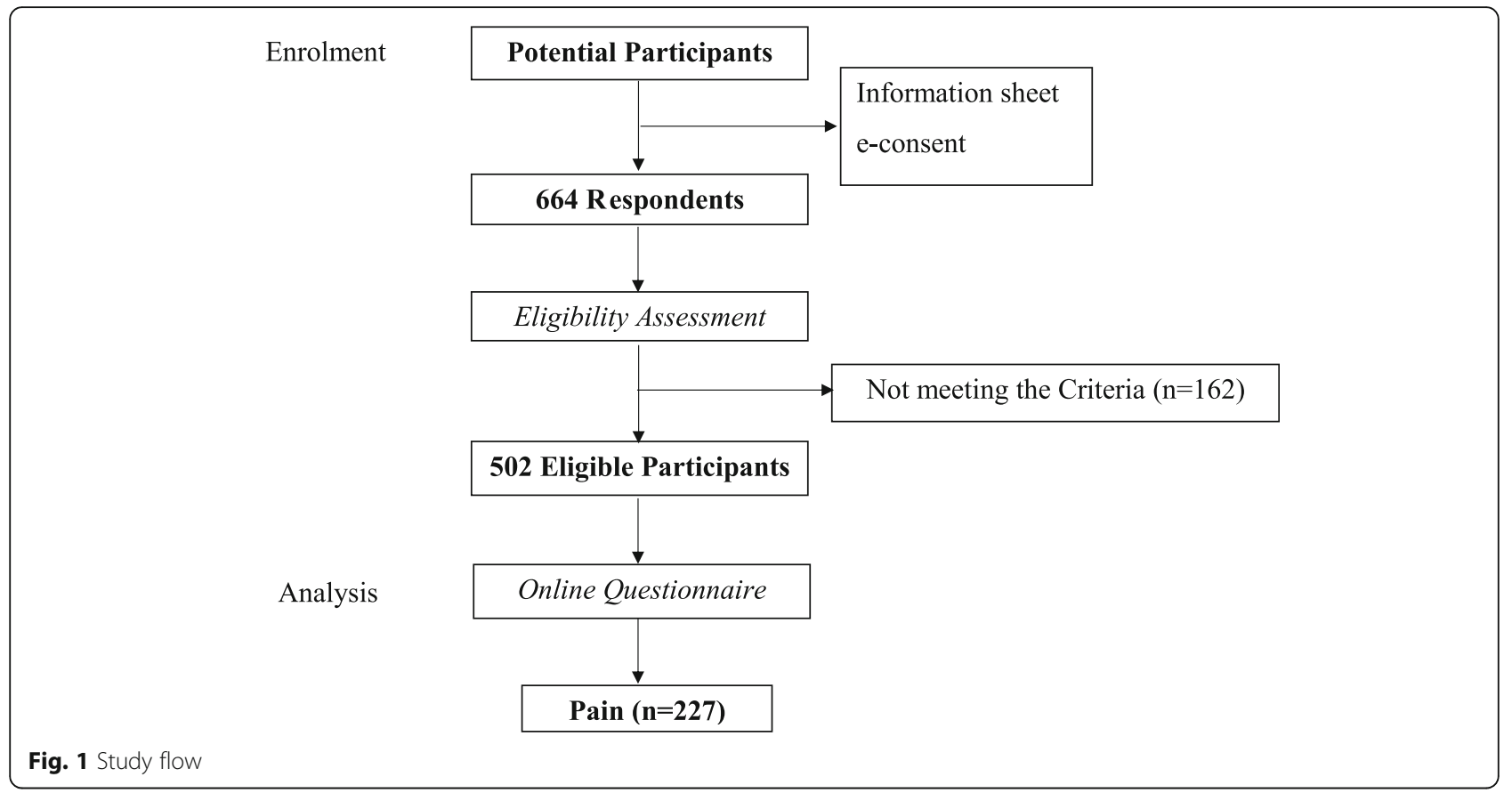

think there is enough education program / public service for pain?" Their interest and willingness towards online pain management program and the potential topics raised by participants for the future online pain education program was also asked in this part. In part 4 and 5, participants' habit of using internet and the demographic data were collected.

\section{Statistical analysis}

All statistical analysis was performed using Statistical Package for the Social Sciences (SPSS). Descriptive statistical analysis (n, \%, mean, and standard deviation) were used to present negative impact of pain, the utilization of pain treatments and the suggested topics. Continuous data was carried out using Chi-Square test to describe the pain intensity, effectiveness of non-pharmacological treatments. To examine the association between sociodemographic factors and pain, independent multiple logistic regression was used. Spearman's correlation was used to assess the correlation between the average pain intensity and sociodemographic factors, pain interfered activities and selfrelieve strategies. A $p$-value of $<0.05$ was considered statistically significant.

\section{Results}

\section{Demographic characteristics}

A total of 664 people answered the online questionnaire and 502 fit the criteria. Among all, 45\% reported pain in the past 6 months. More female participants (63\%) were suffering from pain compared with male (37\%). Those aged 20 to 40 years constituted the largest group in the present study and more than $80 \%$ of the participants had a bachelor's degree or higher education level. Details shown in Table 1.

\section{Pain sites, intensity and interference}

Neck is reported as the most common pain site (68.72\%) followed by shoulder (62.56\%) and back (57.71\%) (Fig. 2). Head (49.34\%) is the fourth common pain sites reported with highest pain score (Mean $=4.23, \mathrm{SD}=2.52)$. The pain score at neck, back and shoulder are $4.10 \pm 2.31$, $3.90 \pm 2.33$ and $3.78 \pm 2.41$ respectively.

Table 2 shows the pain interference. Mood (56.4\%), working (46.7\%) and daily activities (37\%) are most commonly been impacted by pain. Significant correlation is shown between pain intensity and mood $(r=-0.148$, $p<0.05)$, working $(r=-0.194, p<0.01)$, sports $(r=-$ $0.156, p<0.05)$ and entertainment $(r=-0.131, p<0.05)$.

\section{Pain relieve methods and self-perceived effectiveness}

Results show that $20.26 \%$ participants did not take any actions, whereas their pain score is the highest $3.28 \pm 2.64$ on an 11-point scale (Table 3). Non-pharmacological treatments were more chosen $(56.39 \%)$ than pharmacological treatments (23.35\%). Lying down (60.29\%), massage (58.82\%) and hot compress (44.85\%) are the top three used non-pharmacological strategies. Lying down was reported with the highest SPF score (Mean $=3.76, \mathrm{SD}=$ 2.68 ) followed by hot compress (Mean $=3.15, \mathrm{SD}=2.79)$ and massage $($ Mean $=2.93, \mathrm{SD}=2.64)$. 
Table 1 Demographic characteristics

\begin{tabular}{|c|c|c|c|c|c|}
\hline & Total $(n=502) \mathrm{N}(\%)$ & Pain $(n=227,45 \%) \mathrm{N}(\%)$ & No Pain $(n=275,55 \%)$ N (\%) & $p$-value & $r_{s}$ \\
\hline Gender & & & & 0.272 & 1 \\
\hline $\mathrm{F}$ & $303(60.36)$ & $143(63.00)$ & $160(63.49)$ & & \\
\hline M & 199 (39.64) & $84(37.00)$ & $115(45.63)$ & & \\
\hline Age & & & & $0.031 \wedge$ & 0.077 \\
\hline $16-20$ & $24(4.78)$ & $6(2.64)$ & $18(7.14)$ & & \\
\hline $21-30$ & $213(42.43)$ & $100(44.05)$ & $113(44.84)$ & & \\
\hline $31-40$ & $179(35.66)$ & 75 (33.04) & $104(41.27)$ & & \\
\hline $41-50$ & $63(12.55)$ & $30(13.22)$ & $33(13.10)$ & & \\
\hline $51-60$ & $23(4.58)$ & $16(7.05)$ & $7(2.78)$ & & \\
\hline Marital Status & & & & 0.168 & / \\
\hline Married & $356(70.92)$ & $154(67.84)$ & $202(80.16)$ & & \\
\hline Single/Divorced/widowed & $146(29.08)$ & $73(32.16)$ & $73(28.97)$ & & \\
\hline Educational Level & & & & 0.034 & \\
\hline None & $11(2.19)$ & $9(3.96)$ & $2(0.79)$ & & \\
\hline Primary School & $40(7.97)$ & $13(5.73)$ & $27(10.71)$ & & -0.185 \\
\hline Middle school & $46(9.16)$ & $20(8.81)$ & $26(10.32)$ & & \\
\hline College or Above & 405 (80.68) & $185(81.50)$ & $220(87.30)$ & & \\
\hline Occupation & & & & 0.385 & \\
\hline Civil & $35(6.97)$ & $15(6.61)$ & $20(7.94)$ & & \\
\hline Profession & $114(22.71)$ & $62(27.31)$ & $52(20.63)$ & & / \\
\hline Worker & $77(15.34)$ & $28(12.33)$ & 49 (19.44) & & \\
\hline Business/Service & $90(17.93)$ & $38(16.74)$ & $52(20.63)$ & & \\
\hline Farmer & $31(6.18)$ & $12(5.29)$ & $19(7.54)$ & & \\
\hline Producer/Transport & $18(3.59)$ & $8(3.52)$ & $10(3.97)$ & & \\
\hline Soldier & $14(2.79)$ & $7(3.08)$ & $7(2.78)$ & & \\
\hline Others & $123(24.50)$ & $57(25.11)$ & 66 (26.19) & & \\
\hline Income (Monthly, CNY) & & & & 0.566 & \\
\hline$<2000$ & $14(2.79)$ & $4(1.76)$ & $10(3.64)$ & & \\
\hline $2001-3000$ & $22(4.38)$ & $10(4.41)$ & $12(4.36)$ & & -0.303 \\
\hline $3001-4000$ & $28(5.58)$ & $17(7.49)$ & $11(4.00)$ & & \\
\hline $4001-5000$ & $47(9.36)$ & $21(9.25)$ & $26(9.46)$ & & \\
\hline $5001-6000$ & $51(10.16)$ & $26(11.45)$ & $25(9.09)$ & & / \\
\hline $6001-7000$ & $70(13.94)$ & $36(15.86)$ & $34(12.36)$ & & \\
\hline $7001-8000$ & $88(17.53)$ & $39(17.18)$ & $49(17.82)$ & & \\
\hline $8001-9000$ & $91(18.13)$ & $37(16.30)$ & $54(19.64)$ & & \\
\hline $9001-10,000$ & $60(11.95)$ & $25(11.01)$ & $35(12.73)$ & & \\
\hline$>10,000$ & $31(6.18)$ & $12(5.29)$ & $19(6.91)$ & & \\
\hline Living Condition & & & & 0.074 & \\
\hline With Family & 119 (23.71) & $50(22.03)$ & $69(25.09)$ & & \\
\hline With Mate & $115(22.91)$ & $52(22.91)$ & $63(22.91)$ & & \\
\hline With Parents & $104(20.72)$ & $37(16.30)$ & $67(24.36)$ & & \\
\hline With Children & $66(13.15)$ & $33(14.54)$ & $33(12.00)$ & & \\
\hline Along & $63(12.55)$ & $34(14.98)$ & $29(10.55)$ & & \\
\hline With Others & 35 (6.97) & $21(9.25)$ & $14(5.09)$ & & \\
\hline
\end{tabular}

$\wedge$ Chi-Square test was applied, $p$-value $<0.05$ is considered statistically significant 


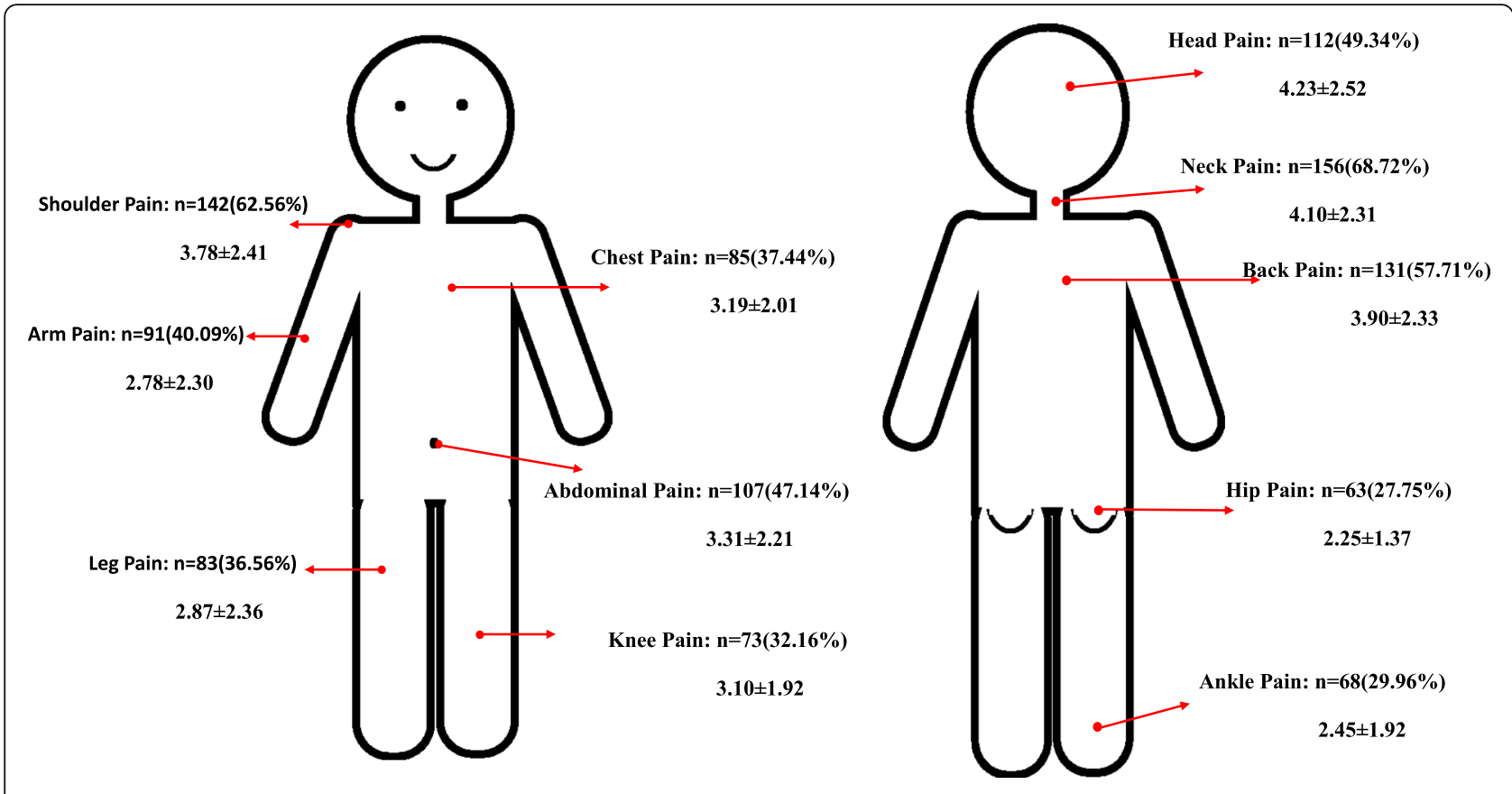

Fig. 2 Pain sites and pain intensity

Willingness to the online pain education program and the potential topics of the program raised by participants Around $64 \%$ of respondents showed interest and willingness in joining the online pain education program. Seventy-four percent respondents would like to learn the influence of pain. Together with pharmacological treatment $(71.74 \%)$ and relationship between pain and disease (67.39\%) were found to be the most attractive topics (Table 4).

\section{Discussion}

Totally 502 participants were studied with $60 \%$ of female participants. Most of the participants were aged between 21 and 40. Pain prevalence was reported 45\% among the working adults. $64 \%$ participants showed willingness in

Table 2 Negative impact of pain

\begin{tabular}{llll}
\hline Items & $\mathrm{N}(\%)$ & $p$-value & $\mathrm{r}^{\mathrm{a}}$ \\
\hline Mood & $128(56.4)$ & 0.026 & $-0.148^{\mathrm{b}}$ \\
Working & $106(46.7)$ & 0.003 & $-0.194^{\mathrm{c}}$ \\
Daily activities & $84(37.0)$ & 0.367 & -0.060 \\
Sleep & $73(32.2)$ & 0.232 & -0.079 \\
Sports & $73(32.2)$ & 0.018 & $-0.156^{\mathrm{b}}$ \\
Relationship & $41(18.1)$ & 0.863 & -0.011 \\
Entertainment & $37(16.3)$ & 0.048 & $-0.131^{\mathrm{b}}$ \\
\hline
\end{tabular}

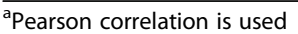

${ }^{\mathrm{b}}$ Correlation is significant at the 0.05 level (2-tailed)

${ }^{\mathrm{c} C}$ Correlation is significant at the 0.01 level (2-tailed) joining in the online pain education program and participants' educational needs were identified.

The present study reported a high prevalence of pain (45\%) among working adults. The pain prevalence is higher than that of the general population in China which was reported $35.9 \%$ in the previous study [7]. Neck, shoulder and back are the most commonly reported pain sites in the present study with high pain score. The results may result by the office automatization policy in China. With the development of the technology and the environment protection nowadays, companies which advocate office automatization are increasing [27]. People are expected to work on the computer, in regard of this policy, long sitting time and computer-facing time are becoming significant factors causing pain especially in neck, shoulder and back among the working adults.

Significant correlation between pain intensity and educational level and income were demonstrated in the present study. The findings are consistent with previous studies. Researches had indicated that the higher risk of pain is correlated with lower sociodemographic status $[7,9,28]$. As it reported by National Bureau of Statistics of China, the average monthly income of Chinese was 2165 Yuan (318 USD) in 2017 and lower in rural area [29]. Accessible medical resources are limited in the rural area and the average education level is lower as well. These restrictions can indirectly lead to a high pain incidence and intensity.

Work is impacted by pain according to the results which is a significant problem especially for the working 
Table 3 Pain relieve methods used by pain suffers and the self-perceived effectiveness of the treatments

\begin{tabular}{llll}
\hline & $\mathrm{N}(\%)$ & Pain score (Mean \pm SD) & Self-perceived effectiveness (Mean \pm SD) \\
\hline Pain relieve methods & & & \\
Do not take any treatments & $46(20.26)$ & $3.28 \pm 2.64$ & - \\
Non-pharmacological treatments & $128(56.39)$ & $2.59 \pm 0.72$ & - \\
Lying down & $82(60.29)$ & - & $3.76 \pm 2.68$ \\
Hot Compress & $61(44.85)$ & - & $3.15 \pm 2.79$ \\
Massage & $80(58.82)$ & - & $2.93 \pm 2.64$ \\
Deep Breath & $49(36.03)$ & - & $2.92 \pm 2.83$ \\
Sports & $55(40.44)$ & - & $2.85 \pm 2.52$ \\
Cupping & $55(40.44)$ & - & $2.78 \pm 2.65$ \\
Plaster & $46(33.82)$ & - & $2.70 \pm 2.61$ \\
Scrapping & $46(33.82)$ & - & $2.70 \pm 2.53$ \\
Acupuncture & $42(30.88)$ & - & $2.55 \pm 2.50$ \\
Reading & $42(30.88)$ & - & $2.53 \pm 2.63$ \\
Cold Compress & $43(31.62)$ & - & $2.52 \pm 2.55$ \\
Talking & $40(29.41)$ & - & $2.52 \pm 2.66$ \\
Music & $44(32.35)$ & - & $2.51 \pm 2.47$ \\
Aromatherapy & $37(27.21)$ & - & $2.38 \pm 2.46$ \\
Pharmacological treatment & $53(23.35)$ & $2.19 \pm 1.87$ & - \\
\hline
\end{tabular}

$N=227$, Total No. of Non-Pharmacological treatments use $=136$

SD Standard deviation

$r$ is calculated using Pearson correlation

Guideline:

Small $r=0.10$ to 0.29

Medium $r=0.30$ to 0.49

Large $r=0.50$ to 1.0

adults. In China, salary is related with the attendance. Longer time asking for leave would lead to lower salary. Due to the lower socioeconomic status, working adults would experiencing more severe pain and the overall quality of life would be impacted. Managing pain is momentous among working adults.

Around one fourth of the participants did not take any actions to manage their pain situation, and this may lead to persistent and worse pain. Non-pharmacological treatments are more chosen perhaps is on account of lacking of time to see doctor, insufficient medication knowledge and the convenient and easy accessibility with low cost. Lying down, hot compress and massage were among the most common non-pharmacological treatments applied and the self-

Table 4 Potential topics of online education program raised by participants

\begin{tabular}{lll}
\hline Topics & $\mathrm{N}$ & $\%$ \\
\hline Physical and psychological impact of pain & 237 & 73.60 \\
Pharmacological treatment & 231 & 71.74 \\
Relationship between pain and diseases & 217 & 67.39 \\
Non-pharmacological treatment & 188 & 58.39 \\
Definition of pain & 180 & 55.90 \\
\hline
\end{tabular}

$N=322$, Total No. of responses to the topics $=1053$ perceived effectiveness were high. Researchers had indicated that use of hot water bag is common and it is an effective methods in pain management $[18,30,31]$. Lying down and massage can be easily self-initiated to relieve pain. Since this kind of pain-relieving strategies are easy and convenient to use, they can be recommended to the working adults.

The patients' demand for pain management programs in China was high. Chu et al. [32] reported a 10-year outcome of pain management program for Chinese suggested that the recurrence of body pain was mainly due to lack of effective pain management programs. In this way, pain management programs are needed. Considering the applicability and advantages of internet together with participants educational needs identified, online pain education programs can be developed. The topics raised by the participants should be involved in the future pain education program.

There are several limitations of this study should be noted. First, the participants' recruitment was following the snowball sampling which was reported may be more biased toward the more cooperative participants who are willing to participate in the study [33]. In regard of this, most of the participants are mainly from three cities which may be less representative to the nationwide 
working population. In addition, the participants gathered more in age group of 20 to 40 years may result of the internet-based recruitment as the internet is more popular among younger population. As the consequence of the younger age group, the pain prevalence reported may be lower than reality, therefore, stratified analyses of pain by sociodemographic factors should be made in the future study.

This study has a number of strengths in spite of the limitations. Firstly, it is the first time to use WeChat as an approach to deliver online survey in China. Secondly, this study specially focus on the working adults which is meaningful in learning pain situation in the specific group. The results contribute to the society to evaluate the overall pain situation. Thirdly, the educational needs of the pain suffers were identified and their willingness in joining the future online program were collected.

\section{Conclusion}

The pain prevalence is high among working adults in China. Impact of pain on work is a significant problem for the working adults. It is important to identify people at risk and deliver timely intervention to reduce pain. People showed their willingness in joining the online program. Therefore, future online pain education program can be developed.

\section{Acknowledgements}

The authors are grateful to all the professionals, families, and friends who contribute to this study.

\section{Authors' contributions}

YJ collected and analyzed data from participants, and was a major contributor in writing the manuscript. MMYT designed the questionnaire and did the modification of the manuscript. Both authors read and approved the final manuscript.

\section{Funding}

Not applicable

\section{Availability of data and materials}

The datasets used and/or analyzed during the current study are available from the corresponding author on reasonable request.

\section{Ethics approval and consent to participate}

The ethical approval is obtained from The Hong Kong Polytechnic University (Reference Number: HSEARS20180519002).

All participants' consent was collected online. After reading the information sheet, people who agree to join in were required to click "Agree" button to start the survey, otherwise they would be regarded as do not agree to participate and the online survey would be unavailable.

\section{Consent for publication}

Not applicable

\section{Competing interests}

The authors declare that they have no competing interests.
Received: 28 February 2019 Accepted: 15 August 2019

Published online: 22 August 2019

\section{References}

1. Hayes S, Hogan M, Dowd H, Doherty E, O'Higgins S, Nic Gabhainn S, et al. Comparing the clinical-effectiveness and cost-effectiveness of an internetdelivered acceptance and commitment therapy (ACT) intervention with a waiting list control among adults with chronic pain: study protocol for a randomised controlled trial. BMJ Open. 2014:4:e005092.

2. Berman RLH, Iris MA, Bode R, Drengenberg $C$. The effectiveness of an online mind-body intervention for older adults with chronic pain. J Pain. 2009;10: 68-79. https://doi.org/10.1016/j.jpain.2008.07.006.

3. Butow $P$, Sharpe $L$. The impact of communication on adherence in pain management. In: Pain; 2013.

4. Hanssen DJC, Naarding P, Collard RM, Comijs HC, Oude Voshaar RC Physical, lifestyle, psychological, and social determinants of pain intensity, pain disability, and the number of pain locations in depressed older adults. Pain. 2014;155:2088

5. Verhaak PFM, Kerssens JJ, Dekker J, Sorbi MJ, Bensing JM. Prevalence of chronic benign pain disorder among adults: a review of the literature. Pain. 1998;77:231.

6. Mohamed Zaki LR, Hairi NN. A systematic review ofthe prevalence and measurement of chronic pain in Asian adults. Pain Manag Nurs. 2015;16: 440-52. https://doi.org/10.1016/j.pmn.2014.08.012.

7. Chen B, Li L, Donovan C, Gao Y, Ali G, Jiang Y, et al. Prevalence and characteristics of chronic body pain in China: a national study. Springerplus. 2016;5:938.

8. Wong WS, Fielding R. Prevalence and characteristics of chronic pain in the general population of Hong Kong. J Pain. 2011;12:236-45. https://doi.org/1 0.1016/j.jpain.2010.07.004.

9. Dear BFN, Gandy MN, Karin EN, Ricciardi TN, Fogliati VJN, Mcdonald SN, et al. The pain course: a randomised controlled trial comparing a remotedelivered chronic pain management program when provided in online and workbook formats. Pain. 2017;158:1289-301.

10. Devineni T, Blanchard EB. A randomized controlled trial of an internet-based treatment for chronic headache. Behav Res Ther. 2005;43:277.

11. Andersson G, Lundström $P$, Ström L. Internet-based treatment of headache: does telephone contact add anything? Headache. 2003;43:353-61.

12. Palermo TM, Eccleston C, Lewandowski AS, de Williams ACC, Morley S. Randomized controlled trials of psychological therapies for management of chronic pain in children and adolescents: an updated meta-analytic review. Pain. 2010;148:387-97. https://doi.org/10.1016/j.pain.2009.10.004.

13. Cosio D, Lin EH. Effects of a pain education program for veterans with chronic, noncancer pain: a pilot study. J Pain Palliat Care Pharmacother. 2013;27:340-9.

14. Nicholas MK, Asghari A, Blyth FM, Wood BM, Murray R, McCabe R, et al. Selfmanagement intervention for chronic pain in older adults: a randomised controlled trial. Pain. 2013;154:824.

15. Keogh E, Rosser BA, Eccleston C. E-Health and chronic pain management: current status and developments. Pain. 2010;151:18.

16. Dear BF, Gandy M, Kdarin E, Staples LG, Johnston L, Fogliati VJ, et al. The pain course: a randomised controlled trial examining an internet-delivered pain management program when provided with different levels of clinician support. Pain. 2015;156:1920.

17. Bender JL, Radhakrishnan A, Diorio C, Englesakis M, Jadad AR. Can pain be managed through the internet? A systematic review of randomized controlled trials. Pain. 2011;152:1740.

18. Yeh M, Chen H, Houng Y, Liao F. A new website: self-management of dysmenorrhea online learning. Beijing Biomed Eng. 2006:25:95-8.

19. Center CINI. 41st statistical report on the internet development in China; 2019.

20. Peng X, Zhao YC, Zhu Q. Investigating user switching intention for mobile instant messaging application: taking WeChat as an example. Comput Hum Behav. 2016;64:206-16.

21. WeChat. 2017 WeChat data report released (full version) 2017. http://www. sohu.com/a/203492754_481775.

22. Tse MMY, Tang A, Budnick A, Ng SSM, Yeung SSY. Pain and pain management among university students: online survey and web-based education. Cyberpsychol Behav Soc Netw. 2017;20:305-13. https://doi.org/1 0.1089/cyber.2016.0580.

23. Lawshe $\mathrm{CH}$. A quantitative approach to content validity. Pers Psychol. $1975 ; 28: 563$. 
24. Naegeli AN, Tomaszewski EL, Al Sawah S. Psychometric validation of the Brief Pain Inventory-Short Form in patients with systemic lupus erythematosus in the United States. Lupus. 2015;24:1377.

25. Wang Xin S, Mendoza Tito R, Gao Shuo-Zheng S, Cleeland CS. The chinese version of the brief pain inventory (BPI-C): its development and use in a study of cancer pain. Pain. 1996;67:407-16.

26. Friesen LN, Hadjistavropoulos HD, Schneider LH, Alberts NM, Titov N, Dear BF. Examination of an internet-delivered cognitive behavioural pain management course for adults with fibromyalgia: a randomized controlled trial. Pain. 2017;158:593.

27. Wang $S$, Xiao D, Ji Z. Eyaluation and improvement of office automatization system. Value Eng. 2010:179-80.

28. Miljković A, Stipčić A, Braš M, Dorđević V, Brajković L, Hayward C, et al. Is experimentally induced pain associated with socioeconomic status? Do poor people hurt more? Med Sci Monit. 2014:20:1232.

29. National Bureau of Statistics of China. 2017 Residents' income and expenditure consumption. 2017. www.limesurvey.org/en/aboutlimesurvey/\%0Areferences.

30. Sever C, Kulahci Y, Uygur F, Karagoz H, Bayram Y, Oksuz S, et al. Burn injury due to hot water bottle. Mod Plast Surg. 2011;1:1-2.

31. Chia CF, Lai JHY, Cheung PK, Kwong LT, Lau FPM, Leung KH, et al. Dysmenorrhoea among Hong Kong university students: prevalence, impact, and management. Hong Kong Med J. 2013;19:222.

32. Chu MC, Law RKY, Cheung LCT, Ma ML, Tse EYW, Wong TCM, et al. Pain management programme for Chinese patients: a 10-year outcome review. Hong Kong Med J. 2015;21:304

33. Petersen RD, Valdez A. Using snowball-based methods in hidden populations to generate a randomized community sample of gang-affiliated adolescents. Youth Violence Juvenile Justice. 2005;3:151.

\section{Publisher's Note}

Springer Nature remains neutral with regard to jurisdictional claims in published maps and institutional affiliations.

Ready to submit your research? Choose BMC and benefit from:

- fast, convenient online submission

- thorough peer review by experienced researchers in your field

- rapid publication on acceptance

- support for research data, including large and complex data types

- gold Open Access which fosters wider collaboration and increased citations

- maximum visibility for your research: over $100 \mathrm{M}$ website views per year

At $\mathrm{BMC}$, research is always in progress.

Learn more biomedcentral.com/submissions 